\title{
Correction to: Statins to mitigate cardiotoxicity in cancer patients treated with anthracyclines and/or trastuzumab: a systematic review and meta-analysis
}

\author{
Mary Obasi ${ }^{1}{ }^{\circledR} \cdot$ Arielle Abovich $^{2} \cdot$ Jacqueline B. Vo $^{3} \cdot$ Yawen Gao $^{4} \cdot$ Stefania I. Papatheodorou ${ }^{5} \cdot$ Anju Nohria $^{6,7}$. \\ Aarti Asnani ${ }^{8}$. Ann H. Partridge ${ }^{7,9}$
}

Published online: 17 September 2021

(c) Springer Nature Switzerland AG 2021

\section{Correction to: Cancer Causes \& Control https://doi.org/10.1007/s10552-021-01487-1}

In the original publication of the article, the formatting of Tables 4 and 5 were incorrect. The correct version of Tables 4 and 5 are provided in this correction.

The original article can be found online at https://doi.org/10.1007/ s10552-021-01487-1.

Mary Obasi

mobasi@mednet.ucla.edu

1 Department of Medicine, David Geffen School of Medicine, University of California, Los Angeles, USA

2 Department of Medicine, Johns Hopkins Hospital, Baltimore, MD, USA

3 Division of Cancer Epidemiology \& Genetics, National Cancer Institute, Rockville, MD, USA

4 Analysis Group, Los Angeles, CA, USA

5 Harvard T.H. Chan School of Public Health, Boston, MA, USA

6 Dana-Farber/Brigham and Women's Cancer Center, Boston, MA, USA

7 Harvard Medical School, Boston, MA, USA

8 CardioVascular Institute, Beth Israel Deaconess Medical Center and Harvard Medical School, Boston, MA, USA

9 Medical Oncology, Dana-Farber Cancer Institute, Boston, MA, USA 
Table 4 Pooled relative risk for incidence of cardiotoxicity using random-effects model

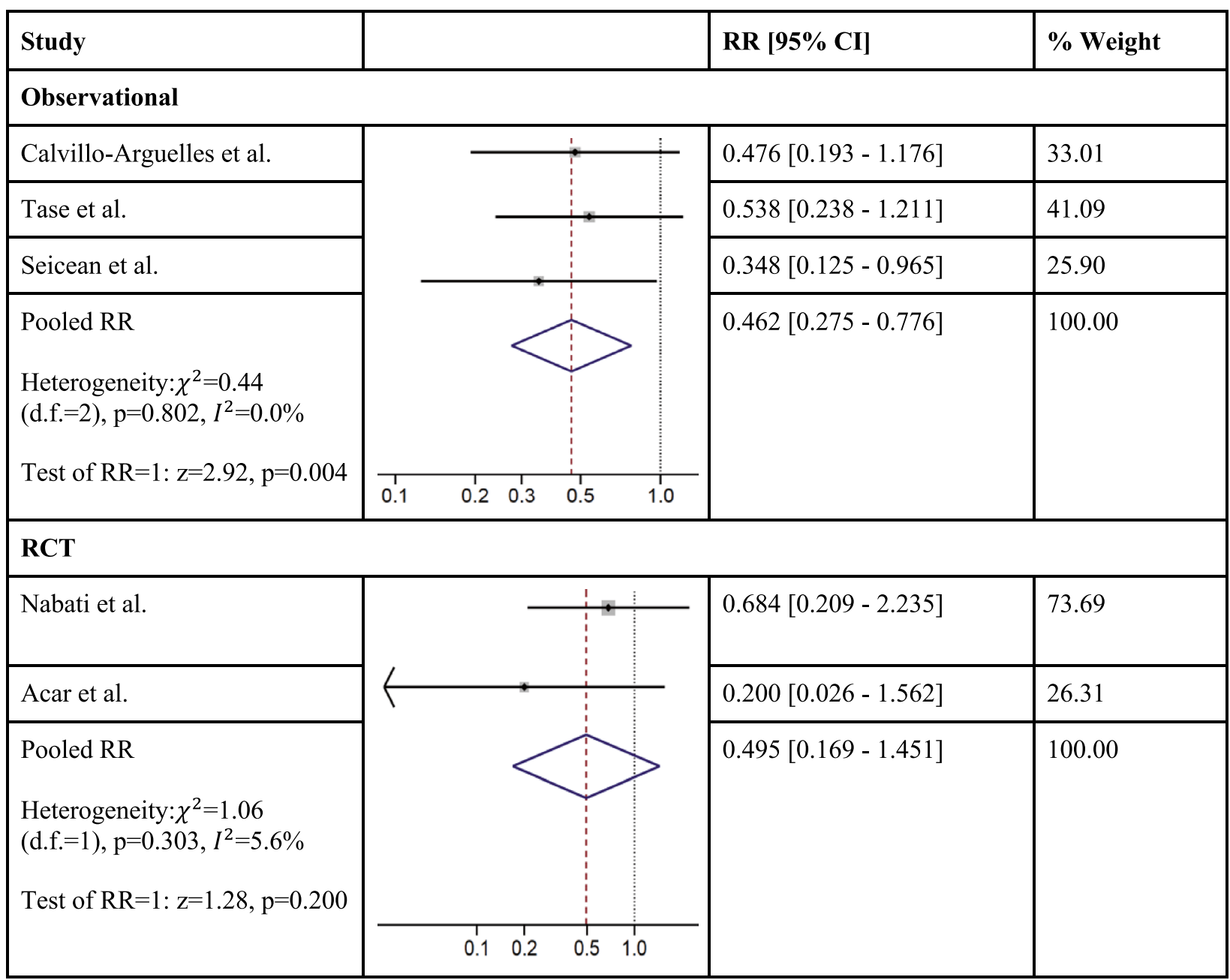


Table 5 Estimated weighted mean difference for change in LV ejection fraction using random-effects model with inverse variance weights

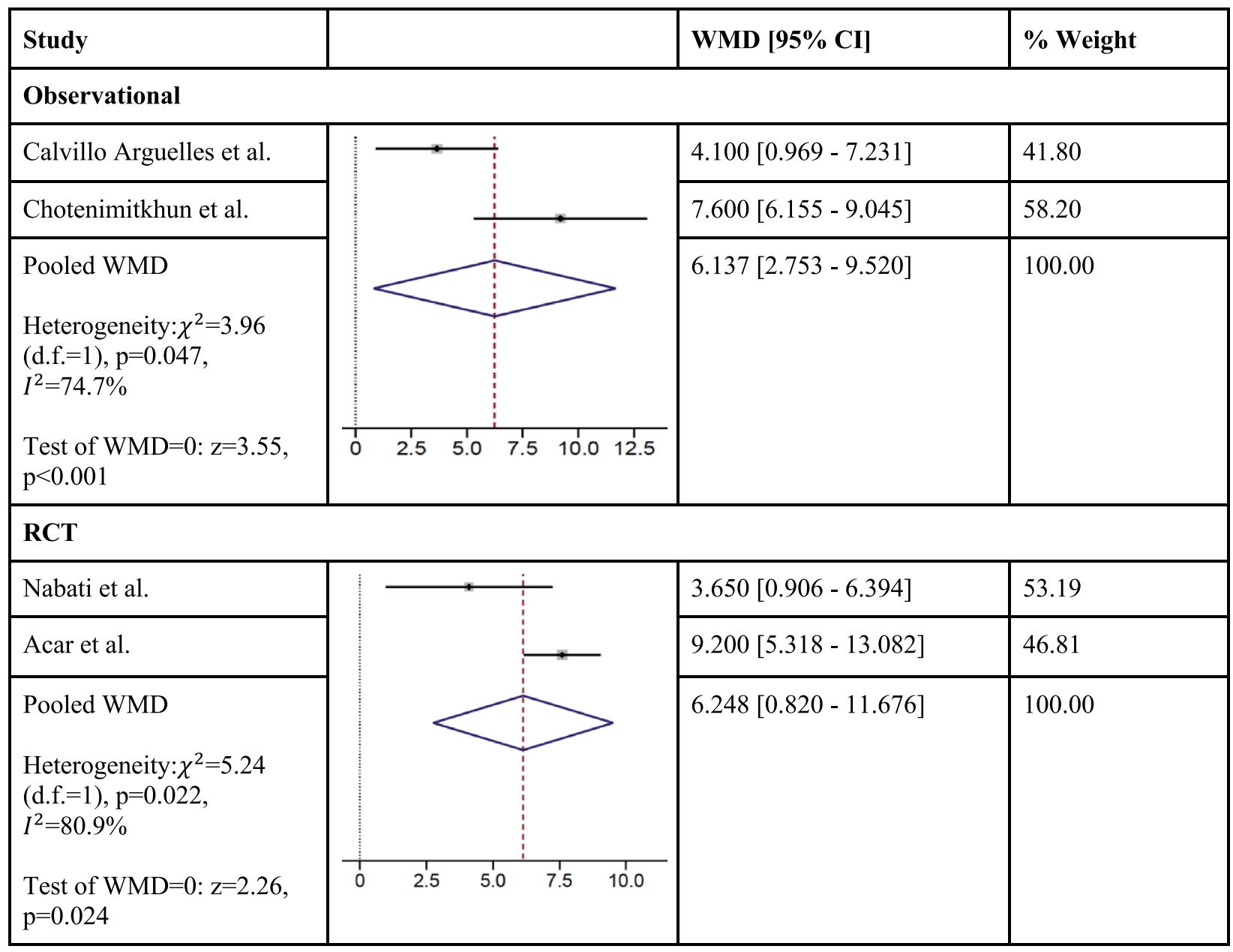

Publisher's Note Springer Nature remains neutral with regard to jurisdictional claims in published maps and institutional affiliations. 